\title{
Negative and positive impact of internet addiction on young adults: Empericial study in Malaysia
}

\author{
Syed Shah Alam¹, Nik Mohd. Hazrul Nik Hashim², Maisarah Ahmad ${ }^{1}$ \\ Che Aniza Che Wel ${ }^{1}$, Sallehuddin Mohd Nor ${ }^{1}$, Nor Asiah Omar ${ }^{1}$ \\ ${ }^{1}$ Universiti Kebangsaan Malaysia (Malaysia) \\ ${ }^{2}$ The National University of Malaysia (Malaysia) \\ shahalam@ukm.my,nikhaz@ukm.my,sara@ukm.my, \\ aniza@ukm.my,smn@ukm.my,norasiah@ukm.my
}

Received July, 2013

Accepted February, 2014

\section{Abstract}

Purpose: The purpose of this study is to explore and identify the impact of Internet addictions on young adults in Malaysia. There are six impacts identified, of which five are negative impacts and one is a positive impact.

Design/methodology/approach: This study comprised a sample of 200 young adults in Malaysia. A cross-sectional research design was used to examine the impact of Internet addiction. Data were gathered based on personal administered questionnaires.

Findings: Mann-Whitney $U$ test results show that the adults those are using Internet excessively were having some problems such as interpersonal problem, behavioural problem, physical problem, psychological problem, and work problem in their daily life. The young adults believed that the Internet usage can help them to improve their skills for doing their work better. This study also reveals that males were likely having working problems, psychological problems, behavioural problems and interpersonal 
problems than female. On the other hand, females were having their physical problems while using Internet excessively.

Research limitations/implications: The data for this study are collected by selfadministered questionnaires, a method with well-known shortcomings. Secondly, the sample size itself is relatively small. This study can be strengthened by increasing the sample size and including participants in other geographical areas in Malaysia.

Practical implications: The present study reveals five negative impacts i.e. interpersonal problem, behavioural problem, physical problem, psychological problem, and work problem for excessive Internet usage. Government agencies like Health department of Malaysia and other government agencies should create better awareness of the problem having while using Internet. It can be done by having seminars or introduction sessions at all universities in Malaysia.

Originality/value: The findings are original and unique and are based on the literature from different western researches. The results are based on a sample of young adults in Malaysia. The research findings are useful to academics and heavy Internet users who are hooked with Internet to their everyday life.

Keywords: Internet addiction, young adults, Malaysia

Jel Codes: M15, L86

\section{Introduction}

Since 1990s Internet users rapidly increasing and it is become one of the most important topic for the research (Rotsztein, 2003).

As the growing phenomenon of vast browsing of the Internet; now-a-days researchers are trying to identify what are the impacts of heavy Internet usage, specifically for the young adults (Morahan-Martin, 2005). A previous study has found $83.4 \%$ of the frequent Internet users age between twenty years to forty years (ZDNet Research, 2006). In addition, 30 of them browsing the Internet without any specific reason, $67 \%$ of them are male and one more vital issue is that young adults act much like teens in their tendency to use sites, where $72 \%$ of them are engaged in social networking, days and nights (PewResearch Center, 2010).

During the last two decades, the way we live and the way we work has changed due to the developments in the communication and information industries (Unsal, Ruzgar \& Ruzgar, 2008). The reasons behind this is the wide distribution of computers, whereby communication 
among people takes place in virtual space, better known as cyberspace (Kim, 2008). This cyberspace has appeared as a new environment which is basically different from the real world we live in, as it is has linked peoples all over the world, increase efficiency at learning, we can use cyberspace for acquiring and disseminating knowledge in order for further development. Currently, based on the latest data published by Internet World Stats, there are approximately 2 billion people in the world having Internet access. The growth of Internet usage has increased tremendously to $566.4 \%$ from year 2000 to 2012 . The fastest growing group is the category of adult aged 55 and above, while those in group 18-34 of age represent the most active online users (Pastore, 2000).

Principally, Asia has the highest number of Internet users in the world, approximately 922.3 million, representing $44 \%$ share of the world's Internet user population, according to data by Internet World Stats. In Asia, there has been a growing concern on what has been labelled "Internet addiction." It has been seen as a serious public health issue in certain Asian countries (Hechanova \& Czincz, 2009). In Beijing, Shan Xiuyun, a leading judge, has said that $90 \%$ of juvenile crime in the Beijing city was Internet-related (Sebag-Montefiore, 2005). According to Chinese Ministry of Health, staying online more than six hours a day and having adverse reactions from not being able to go online, are symptoms of Internet addiction disorder (Williams, 2008). The Governments of China, Japan and South Korea have set up boot camps, to provide therapy to deal with Internet addiction as a result of this (Ransom, 2007). China will begin to ban the opening of new Internet cafes as a government campaign to clamp down on Internet addiction (Watts, 2007).

A number of research has also been conducted on the impact of Internet addiction and other related problems and has found that Internet users exhibit disturbed behaviour on the Internet (Martin, 2001). Furthermore, another study has found that $15 \%$ of university students in the United States and Europe know that they are somehow addicted to the Internet (Anderson, 1999). Yet, there are also some who doubt whether this outcry is justified. Most of the academic research on Internet addiction conducted in USA (Fitzpatrick, 2008), South Africa (Thatcher \& Goolam, 2005), South Korea (Ko, Yen, Chen, Chen, Wu \& Yen, 2006), Taiwan (Tsai \& Lin, 2001; 2003), Italy (Ferraro, Barbara, Antonella \& Marie, 2007), Cyprus (Bayraktar \& Gun, 2007). However, in Malaysia no study has examined the impact of Internet addiction. De Angelis (2000) claimed that much of the research done in this subject utilizes self-selected samples with no control groups.

However, a psychiatrist in Malaysia, Dr Muhammad Muhsin Ahmad Zahari does recognise Internet addiction as a problem; he added that there are lacking of papers, academically and scientifically that could determine the level of Internet addiction in Malaysia (Solomon, 2009). 
In Malaysia Internet users have increased tremendously resulting $60.7 \%$ of the entire population encompass access to the Internet (Internet World Stats, June, 2012). Thus, we conducted an empirical study and discovered the impact of excessive Internet usage in Malaysia.

Consequently, it is important that due to this controversy, several questions can be raised to examine the level of Internet addiction in Malaysia. This could mean reviews by academic and empirical literature to address few questions:

- Does Internet addiction cause problems;

- Which personality type correlates with Internet addiction; and

- What are the characteristics of Internet users and possible addicts

The purpose of this paper is to review the literatures available by other researches in the globe to date and, to explore the impact of Internet addiction on young adults in Malaysia.

\section{Literature review}

\subsection{Concept of Internet addiction}

Internet addiction, as an impulse control disorder that does not involve the use of an intoxicating drug and is very similar to pathological gambling (B. Young, 2006). It is defined as a non-chemical or behavioural addiction that involves human-machine interaction, that can be either passive, such as viewing movies or active, such as playing computer games (Widyanto \& Griffiths, 2006). Moreover, Internet addiction is defined as a maladaptive use of the Internet that can lead to social and functional impairment (Solomon, 2009).

The concepts of Internet addiction can be viewed from different aspects such as according to Davis, Flett and Besser (2002) and Shapira, Goldsmith, Keck, Khosla and Mcelroy (2000) inability of individuals to control their use of the Internet, which then causes psychological, social, school, and/or work difficulties. Commenting on the Psychological point of view, Kandell (1998) argued that due to increasing tolerance to the effect of being online, increase number of investment of sources on Internet related activities, unpleasant feelings when off-line, and denial of the problematic behaviours are main reasons for dependent on the Internet.

There are numerous models that have been proposed to categorize various types of online activities. It can be concluded that, a similarity across these models has been the differentiation between interactive and information gathering functions. Early empirical studies 
carried out by K.S. Young (1998) categorised Internet addiction to five specific subtypes such as:

- Cyber-sexual addiction (use of adult chat rooms or cyber-porn);

- Cyber-relationship addiction (over involvement in online relationship);

- Net compulsions (online gambling, online shopping, online trading);

- Information overload (compulsive web surfing or searches) and

- Computer addiction (obsessive computer game).

Indeed, Young's (2001) approach of five phases of Internet addiction process belongs toward the users such as:

- Discovery;

- Experimentation,

- Escalation;

- Compulsion; and

- Hopelessness.

Now-a-days individuals are getting hooked on the Internet such as on pornography, Internet gambling, online shopping, searching for non-important information or chatting for a very long time. It could be happen because, it is compulsory for the students to use Internet, working with the Internet is effective and productive, and feeling comfortable with online friends than the real one, playing games online and also easy Internet access to all mobile devices including smartphone, tablet or other mobile devices (Solomon, 2009). In addition, when it is during online states the addicted young adults feels excited, thrilled, uninhibited, attractive, supported, and more desirable. Whereas, offline situations make him and/or her frustrated, worried, angry, anxious, and depressed. These strong positive emotions reinforce the compulsive behaviour refers to that Internet addiction of young adults create a numbing effect (Young, 1999).

On the other hand, the Internet brings the world so close together today, by its positive aspects such as conducting research, performing business transactions \& communications, accessing library journals, and communicating with social relations, etc. Unfortunately, the Internet is misused by some groups of individuals. Some individuals tend to get obsessed in midst of getting exposed and familiarised with the Internet (Sukunesan, 1999). There are also various opinions on Internet addiction. As common saying, it is not an addiction if someone is 
addicted to anything and it is knowledge (Kim, 2008). However, Young (1998) thinks that it could be hazardous to someone's mental and physical health if Internet is being used excessively.

\subsection{Internet addiction in Asia-Malaysia}

There have been dramatic increases in the use of Internet in Asia, herein particularly in Malaysia. The year 1995 is considered as the beginning of the rising age of the Internet in Malaysia. Malaysia was rank 10th in Asian countries Internet usage perspective of which 177.23 million of Malaysian have Internet (Internet World Stats, 2012). Total Internet users in China (538 million) followed by Japan (101 million), India (137 million), South Korea (40.3 million) Internet users. The Internet serves different purposes depending on the user in Asia. According to Hechanova and Czincz (2009) Internet is being used by the teenagers in Singapore to obtain information on sports, entertainment, science and technology and hobbies. In a study done in Taiwan, it is found that Internet is being used by individuals for games, information searching, entertainment and chatting (Jung et al., 2005). In Malaysia, people set up profiles, upload photos and add friends on social networking sites to keep in touch and share events with friends (Chandra, 2011).

A wide range of Internet addiction from $2.4 \%$ to $12.90 \%$ (Hechanova \& Czincz, 2009) was measured using Young's criteria of addiction, the Internet Addiction Test (IAT), in China. According to the study it is found that the average addiction rate in China is $7.70 \%$ (standard deviation 3.58). In Taiwan, it reveals a much higher average Internet addiction rate of $17.55 \%$ (standard deviation 9.26) from 5 studies carried out. While in Hong Kong, studies carried out on a random sample of 976 respondent aged 16 to 24 , found that $37.9 \%$ can be classified as Internet addicts (Hechanova \& Czincz, 2009). In a nutshell, based on the studies done, the Internet addiction rate in Asia has a large range, (between $2.4 \%$ to $37.9 \%$ ).

\subsection{Young adults}

Literature written for people ranging from ten years up to the age of twenty is counting as young adults. Young adults' generally means the group of people who is aged between 20 and 40. The healthiest time in life is during young adulthood and young adults are in good health without suffering from any diseases. At the age between 20-35 years, the biological function and physical performances reach the peak and start weaken after the age of 35 . Flexibility of the body decreases with age throughout adulthood (Erikson, 1950). 


\subsection{Effect of Internet addiction}

There are numerous impacts of Internet addiction found from the previous research. The negative impacts of Internet addiction includes, the impact on interpersonal relationship where the relationship of an individual is getting further from surrounding (Morahan-Martin, 2005). Individual might face behavioural problem due to over usage of Internet where they are reacting differently than the normal behaviour (Kubey, Lavin \& Barrows, 2001). Some other physical problem might occur due to long use of the Internet. Some physical problems are migraine or headache, sleep pattern disrupt etc (Jeon, 2005; You, 2007; and Yang \& Tung, 2004).

Some other problems include psychological problems where an individual are unable to control their emotions and the way of thinking due to long hour use of the Internet. They tend to increase the net serving time and eliminate the set schedule. Moreover, the impact of Internet addiction does not limit to affect an individual only but might also affect the work performance of an individual (K.S. Young, 2008). The condition is getting worried when the work problem has brought some impacts to the people working together and to the company that the individual is working with. Putting aside the negative impacts, Internet addiction however brought some positive impacts to the user. The Internet provides users with information, connecting worldwide, promoting research, work with other people from overseas country effectively.

Previous studies were conducted in various countries like Taiwan, Italy and Pakistan to determine the impact of Internet addictions for heavy users. Theories are developed throughout the researches to assess the negative and positive impacts of Internet addictions. Those researches, researchers used different theories and amended Theories are varies and based on the culture and environmental situation of the country. K.S. Young's (1998) version of Internet Addiction Test (IAT) was applied in Italy and French studies, but the researchers for the respective countries amended some characteristics to the test to suit the culture of the respondents. In a study conducted in Pakistan, Internet Effect Scale (IES) were constructed by the researchers to test similar impact on the respondents. Hence, for this study, applied was the similar version of IES but factor on Internet Abuse is eliminated in the investigation as the questions proposed were considered sensitive to the Malaysian culture.

There are six effects of Internet addictions derived from the literature review. Those are taken as measures for this study and are discussed below: 


\subsubsection{Interpersonal problem}

Interpersonal problems are recurrent difficulties in relating to others (Loke, 2005). It could be argued that interpersonal problems are the problem people react differently in a situation where other peoples in that situation expecting other ways. The interpersonal aspect was important for the Internet users. According to Li and Chung (2006) those who use the Internet for long time for social function purposes might be having some problems such as the compulsive use of Internet, withdrawal from social activities, decrease the tolerance, facing time management problem, interpersonal and health problems. The researcher also argued that excessive Internet users exhibit more severe Internet addictive behaviours. The extent of Internet use increases depression and decreases self- esteem (Jeon, 2005; Young, 2006; Yang \& Tung, 2004). Wellman and Gulia (1999) reported that online relationships can be strong and could strengthen real world relationships but later it could be faded it. As such, $75.5 \%$ of respondents prefer to use the Internet when they feel isolated; $50 \%$ of respondents reported complaints from family members for being online for longer hours; less than $50 \%$ of respondents think that they were more effective online than offline (Shuhail \& Bergees, 2006).

The relationships between excessive Internet usage and interpersonal problem are increasing rapidly. Li and Chung (2006) stated that it is very important to know how Internet users formed their relationship with their friends through online or normal social life. According to them it is also necessary to check whether the people are missing their social engagement, whether they more comfortable with online friend and reduce the contact with the people in reality or not. In addition, the interpersonal problems are also identifiable based on the family members' complaints toward excessive Internet users'. Furthermore, isolated feeling that leads to excessive Internet usage can also be used to determine interpersonal problems (Wellman \& Gulia, 1999; Shuhail \& Bergees, 2006).

\subsubsection{Behavioural problem}

Bandura (1999) suggests that "Behaviour" is based on internal personal factors including cognitive, affective and biological events and conditions of the external environment that influence each other bi-directionally. A study conducted by Brenner (1997) and Scherer (1997) concluded that time mismanagement effects are generally associated with heavy Internet use. Another study conducted by Kubey et et al. (2001) suggested that heavy recreational use of the Internet among a group of 572 college students was correlated with additional problems including; late evening use, social isolation and sleep disturbances and a decline in academic performance. Half of the respondents in the Pakistan study had to reschedule their activities to 
compromise with online hours, and they skipped meals for being online (Shuhail \& Bergees, 2006).

Kubey et et al. (2001) study examined the behaviour problems and determined how the respondents behave differently compared to usual. This research analysed whether the respondents always need to reschedule their time due to heavy Internet usage. Other researchers also conducted researches on the time spent on the Internet usage in behavioural perspective (Brenner, 1997; Scherer, 1997).

\subsubsection{Physical problem}

Heavy Internet users were much less likely to engage in the following health promoting behaviours than the rest; attempting to eat a healthier diet, taking nutritional supplements, trying to increase physical activity levels, and were shown to be significantly more likely to be overweight Body Mass Index (BMI $>25$ ), have hypersomnia ( $>10 \mathrm{~h}$ of sleep/day) and have adverse effects on their studies (Jean, Lau, Cheuk, Kan, Hui \& Griffiths, 2010). The adverse effect would be; migraine or headache, less sleep, and backaches because of prolong hours of Internet usage (Shuhail \& Bergees, 2006). Sleep patterns are disrupted due to late night logins which resulted to excessive fatigue, impairing academic or decreasing occupational performance, and may decrease the immune system, leaving the addict prone to disease. Sitting at the computer for longer hours also means that addicts are at higher risk in developing carpal tunnel syndrome (K.S. Young, 2004).

The previous studies have found that excessive Internet use brings several physical problems such as backache and other body aches after Internet users spent a long time in the Internet (Young, 2004). The duration of sleeping time will be used to see the respondents' passion in surfing the Internet. On the other hand, the fatigue faced by the Internet users also will determine the Internet addiction impact to the young working adults. Migraine or headache problems also will show the correlation effects with excessive Internet usage (Shuhail \& Bergees, 2006; Jean et al., 2010). 


\subsubsection{Psychological problem}

Rotter (1966) originally described the psychological construct of locus of control as an element of personality. Locus of control refers to the perception of the extent to which individuals can control events in their lives. The research by Rotsztein (2003) suggested that the higher the (external) locus of control score (i.e., those who feel that events in their lives are out of their hands) a student has, the more likely they were to have reported problems due to Internet use. Internet addiction also appears to frequently co-occur with psychological disorders such as; other compulsive behaviours and depression (Young, 1998). Studied by Ferraro et al. (2007) in Italy argued that if anybody spent a lot of time using the Internet are probably the most addicted, the addicted person felt the coercive need to be connected again with Internet.

Psychology is the science of mind and behaviour (Young, 1998). Therefore, to evaluate its' correlation with heavy Internet usage, this research asked the respondents whether they are experiencing restlessness, irritability, anxiety, and low mood when they are staying for a long time on the Internet. The mind of respondents whether in pleasure and satisfaction mood during online is also used as an analysis of this research. The attempt to avoid stress and problems by using Internet is also one of the psychological problems evaluated in this research (Rotter, 1966; Ferraro et al., 2007).

\subsubsection{Work problem}

Many employers have recognized that unlimited use of the Internet by employees has the potential to reduce, rather to than enhance productivity (Young, 2010). A study conducted by Landers and Lounsbury (2004) in testing personality traits with Internet usage suggested that the negative relationship between Work Drive and Internet usage may simply reflect that Internet users who spend a lot of time on the Internet do so at the expense of time that could be spent on studying hard and giving extra effort to get good grades. Indeed, the significant negative correlation between Work Drive and percentage of Internet time classified as Leisure supports the notion that Internet usage is motivated by non-work (i.e., leisure) pursuits. Also, frequent Internet usage may not be functional for more hardworking students. Hence, employees who engaged in non-essential Internet usage on their work have been considered as having a lower work ethic (Ritterskamp, 2003). Employed Internet users were more at-risk for developing an Internet Addiction Disorder (IAD) than unemployed ones; and they perceived their social and individual quality life more compromised (Ferraro et al., 2007). Bakken, Wenzel, Götestam, Johansson and Oren (2009) studied on Internet addiction among 
Norwegian adults and found that unsatisfactory financial situation is one of the factors that associated with Internet addiction.

The excessive Internet usage will cause the delay of work accomplished (K. Young, 2010). Due to the Internet usage, some of the respondents maybe surfing Internet for personal purposes during working hours, and it ends up the workers need to work overtime to finish their work. With that, this research also aims to find out the work performances of the workers due to the excessive Internet usage (Landers \& Lounsbury, 2004; Bakken et al., 2009; Ferraro et al., 2007).

\subsubsection{Positive effect}

The Internet has positive aspects including informative, convenient, resourcefulness and fun, but for the addicts, these benefits become detriments. There are some opinions on Internet addiction (Kim, 2008). A great majority of the respondents in Pakistan study (84\%) reported that Internet is helpful for worldwide communication; 74\% experienced improvement in their reading, writing and information processing skills by using the Internet (Shuhail \& Bergees, 2006). Kaye and Johnson (2004) stated that Internet users are more actively involved and engaged in using the Internet because of its interactivity. Papacharissi and Rubin (2000) used their Internet usage scale and identified five motivations for using the Internet namely; interpersonal utility, pass time, information seeking, convenience, and entertainment. Roy (2009) found out that Internet users experienced self- development, wide range of exposure, relaxation and leisure, and higher global exchange of information and views.

Besides that, Internet usage had helped the young working adults also in their life (Roy, 2009). Essentially, the Internet has a lot of benefits to the users and for the young working adults. It is significant to see whether Internet is a helpful tool in their work to improve work performances by expending the respondents reading, writing and information processing skills. Finally, this is required to identify whether the Internet has made the world wide communication possible to the respondents and has helped them in working as well (Kim, 2008; Shuhail \& Bergees, 2006).

\section{Research Methodology}

In the process of determining Internet addiction, should also be included online activities or application such as chat rooms or online games. According to Young (1998), heavy Internet users always use two way communication functions in the Internet such as chat rooms, role- 
playing games (e.g., Multi-User Dungeons or Multi-User Dimensions) also known as MUDs), newsgroups, or email. Whereas non- heavy Internet users most likely used Information Protocols and the World Wide Web (WWW) for information gathering purposes.

However, the research is undertaken to determine the negative and positive consequences on excessive usage of the Internet among young adults. As such, there is no dependent and independent variable in this study. Previous published literatures were reviewed, and developed and evaluate the impact by using Mann Whitney $U$ test to identify the relationship with all negative and positive impact of Internet addiction and the gender groups (male and female) but no hypotheses were developed for this research.

To investigate the overall problems faced by young Internet users, the following research methodology was employed in this study:

\subsection{Sample}

A questionnaire survey was conducted in March and April 2012. Data for this study was gathered by primary data collection method through consumer survey administered among undergraduate students from two public universities in Malaysia. An in-depth interview was conducted with five lecturers from one university before the final survey was conducted in order to identify the key elements to be asked in the questionnaire. A total of 400 respondents were approached of which 205 responded. Due to the personally administered survey researchers personally checked all questionnaires to make sure that every item in the questions filled up by the respondents properly but even so, there were seven questionnaires did not filled up completely. Out of the seven, two were corrected through a discussion with the respondents identified. But the other five, there were some missing data and it was difficult to relocate the respondents. These five questionnaires were omitted to enhance the validity of this study. Most of the rejected questionnaires are found to be incomplete especially if they did not answer questions pertaining to the variables of interest. In this study, students were selected as the population in view of the experience that they have in using the Internet and very much addicted to the Internet. This will greatly support the objectives of the research. In addition, some studies did suggest that young-adults are suitable group to be considered for the research because they play an important role to change society and culture (Leslie, Sparling \& Owen, 2001). 


\subsection{Reliability testing using Cronbach's alpha}

The internal reliability of the items was verified by computing the Cronbach's alpha. Hair Anderson, Tatham and Black (1998) suggested that a minimum alpha of 0.6 sufficed for early stage of research. The Cronbach alpha estimated for interpersonal scale was 0.7585 , physical scale was 0.7567 , work problems scale was 0.8405 , psychological scale was 0.8084 , and behavioural scale was 0.7509 . As the Cronbach's alpha in this study were all much higher than 0.6 , the constructs were therefore, deemed to have adequate reliability.

\section{Results}

The descriptive results show (Table 1) from 200 respondents, the most affect of Internet addiction impact is on Psychological aspects $(M=3.45)$ and Interpersonal aspects $(M=3.26)$, followed by Physical problems $(M=2.98)$ and Work problems $(M=2.58)$, and finally, Internet addictive Behavioural problems $(\mathrm{M}=2.55)$. In addition, variables associated with Work and Psychological aspects showed maximum impact is 7.00 ; followed by Interpersonal problems 6.71. Whereas, Behavioural and Physical problems illustrated 6.50.

\begin{tabular}{|l|r|r|r|r|r|}
\hline \multicolumn{1}{|c|}{ Variables } & N & Mean & Std. Deviation & Minimum & Maximum \\
\hline Interpersonal & 200 & 3.2645 & 1.09209 & 1.00 & 6.71 \\
\hline Behavioural & 200 & 2.5525 & 1.05668 & 1.00 & 6.50 \\
\hline Physical & 200 & 2.9850 & 1.36163 & 1.00 & 6.50 \\
\hline Work & 200 & 2.5850 & 1.39553 & 1.00 & 7.00 \\
\hline Psychological & 200 & 3.4538 & 1.23625 & 1.00 & 7.00 \\
\hline
\end{tabular}

Table 1. Represent the Descriptive Analysis of Variables

\begin{tabular}{|l|r|r|r|r|r|}
\cline { 2 - 6 } \multicolumn{1}{c|}{} & Interpersonal & Behavioural & \multicolumn{1}{c|}{ Physical } & \multicolumn{1}{c|}{ Work } & Psychological \\
\hline Mann-Whitney U & 4407.00 & 4336.00 & 4742.50 & 3788.50 & 4220.00 \\
\hline Mean rank & 105.41 & 106.30 & 99.78 & 113.14 & 107.75 \\
\hline Male & 97.23 & 96.63 & 100.98 & 92.07 & 95.67 \\
\hline Female & 8433.00 & 8504.00 & 7982.50 & 9051.50 & 8620.00 \\
\hline Sum of ranks & 11667.00 & 11596.00 & 12117.50 & 11048.50 & 11480.00 \\
\hline Male & -.981 & -1.161 & -.144 & -2.561 & -1.449 \\
\hline Female & 0.327 & 0.246 & 0.886 & 0.010 & 0.147 \\
\hline Z
\end{tabular}

Table 2. The relationship between gender and Impact of Internet addiction (Mann-Whitney $U$ test)

Mann-Whitney $U$ test was carried out to test the relationship between gender and impact of Internet addiction on young adults. The relationships between all the variables are shown in Table 2. According to the results of Mann Whitney-U test, the statements which have shown 
the difference between two gender that Internet addiction on males has a great impact on their Working problems than females; i. e., mean ranks is ( $M R=113.14 \& 92.07)$; and then Psychological aspects is ( $M R=107.75$ \& 95.67); Behavioural problems ( $M R=106.30$ \& 96.63); Interpersonal problems $(M R=105.41 \& 97.23)$ for males and females respectively. On the other hand, Internet addiction on females mostly suffered on their Physical problems comparatively to males $(M R=99.78 \& 100.98)$.

\section{Discussion and Conclusions}

Addiction refers to irrepressible urge which is often accompanied by loss of control. Hence, Internet addiction imparts that peoples develop problems from their uncontrollable abuse of Internet usage which is associated with other pathologies such as depression, loneliness and social anxiety (Caplan, 2001; Shapira et al., 2000). As a result, it is difficult to determine the causality of Internet addictedness. Indeed, the impact of Internet addiction recognized as the bundle of dilemma such as; psychological aspects, interpersonal, physical, work and behavioural problems (Young, 2004).

Essentially, this study found that the major group of compulsive Internet usages is young adults. Therefore, their dependence on the Internet and problematic Internet use are the causes behind their Internet addiction disorder, i.e.; firstly, problems related to relationships which refers to spending excessive amount of time starting and maintaining online friendships in chat rooms, which replace real life friends and family. Second, wasting of money by engaging in compulsively using the Internet for gambling online, trading and part-taking in online auctions. Third, dilemma associated with information searching by obsessive web surfing or database searches. Forth, habitual gaming practices such as computer game playing, including multi user games. Finally, sex addiction of young adults is a massive problem through adult chatrooms, cyber sex or pornography on the Internet.

Society in general will need to brace itself for the explosion of online sex coming through devices. Additionally, those who exercise compulsive usages of the Internet are declining their school/college performance and as consequences, would turn down school/college results by getting poor performance and withdrawal from academic social activities and events as well. Subsequently, academic institution such as universities, colleges and school campuses will need to regulate students' use of such kind of wireless devices to reduce the abuse of the Internet.

Internet abuse or Internet addiction of young adults can lead to serious problems for the individuals, particularly the young generations who are at the time of growing their mental and 
physical health. In fact, as the Internet permeates our lives at home and work environment, personal and social phenomenon this study focuses on these Internet abuse impact issues on young adults. Especially, the awful impact of psychological aspects, interpersonal relationships, physical problems and work problems such as poor work performance. Moreover, the academic impact of student Internet abuse and addiction as well. Research on impact of Internet addiction on young adults is in an early stage of development. Thus, it is needed that empirical research on various patterns of distressed users and the patterns of behaviour and/or disorder for future research to remark advanced phenomenon.

\section{Limitations and Future research Directions}

The present study lends interesting insight into assessing to the limited body of knowledge on Internet addiction for young adults in Malaysia. Like other empirical researches, this study is not without its limitations. Our sample is consisted of students from two universities in Malaysia. So, the sample is small in number. The study can be strengthened by increasing the sample size and including participants from other working adults from different part in Malaysia. Longitudinal studies that use both quantitative and qualitative techniques are required to understand the changes on prior and post Internet addiction behaviour. Finally, it is expected from other researchers to do survey on different age group to contribute to this area of research.

\section{References}

BAKKEN, I.J.; WENZEL, H.G.; GÖTESTAM, K.G.; JOHANSSON. A.; OREN, A. (2009). Internet Addiction among Norwegian Adults: A Stratified Probability Sample Study. Scandinavian Journal of Psychology, 50(2): 121-127. http://dx.doi.org/10.1111/j.1467-9450.2008.00685.x

BANDURA, A. (1999). Self-efficacy: The Exercise of Self-control. New York: W.H. Freeman and Company.

BAYRAKTAR, F.; GUN, Z. (2007). Incidence and Correlates of Internet usage among Adolescents in North Cyprus. CyberPsychology \& Behavior, 10: 191-197.

http://dx.doi.org/10.1089/cpb.2006.9969

BRENNER, V. (1997). Psychology of computer use: XLVII. Parameters of Internet use, abuse and addiction: the first 90 days of the Internet usage survey. Psychological Reports, 80 : 879-882. http://dx.doi.org/10.2466/pro.1997.80.3.879 
CAPLAN, S.E. (2001). Challenging the mass-interpersonal communication dichotomy: are we witnessing the emergence of an entirely new communication system?. Electronic Journal of Communication, 11(1). Available at: http://www.cios.org/www/ejc/v11n101.htm.

CHANDRA, D.R. (2011). Do you have facebook addiction disorder?. Retrieved August 11th, 2011 from: http://www. bumigemilang.com/?p=6046.

DAVIS, R.A.; FLETT, G.L.; BESSER, A. (2002). Validation of a new scale for measuring problematic Internet use: Implications for pre-employment screening. Cyber psychology \& Behaviour, 5: 331-345. http://dx.doi.org/10.1089/109493102760275581

ERIKSON, E. H. (1950). Childhood and society. New York: Norton.

FERRARO, G.; BARBARA, C.; ANTONELLA, A.; MARIE, D.B. (2007). Internet Addiction Disorder: An Italian Study. Cyber Psychology \& Behaviour, 10(2): 170-175.

http//dx.doi.org/10.1089/cpb.2006.9972

FITZPATRICK, J.J. (2008). Internet addiction: recognition and interventions. Archives of Psychiatric Nursing, 22: 59-60. http://dx.doi.org/10.1016/j.apnu.2007.12.001

HAIR, J.F.; ANDERSON, R.E.; TATHAM, R.L.; BLACK, W.C. (1998). Multivariate Data Analysis. (5th Ed.). London: Prentice Hall.

HECHANOVA, R.; CZINCZ, J. (2009). Internet addition in Asia: Reality or myth?. IDRC Digital Library, http://hdl.handle.net/10625/38567.

Internet World Status Usage and Population Statistics. http://www.Internetworldstats.com/asia/my.htm.

JEAN, H.K.; LAU, C.H.; CHEUK, K.-K.; KAN, P.; HUI, H.L.C.; GRIFFITHS, S.M. (2010). Brief report: Predictors of heavy Internet use and associations with health-promoting and health risk behaviors among Hong Kong university students. Journal of Adolescence, 33(1): 215-220. http://dx.doi.org/10.1016/j.adolescence.2009.03.012

JEON, J.H. (2005). The effect of extent of Internet use and social supports for adolescent depression and self-esteem. Unpublished master's thesis, Seoul: The Graduate School of Yonsei University.

KANDELL, J.J. (1998). Internet addiction on campus: The vulnerability of college students. Cyber Psychology \& Behaviour, 1: 11-17. http://dx.doi.org/10.1089/cpb.1998.1.11

KAYE, B.K.; JOHNSON, T.J. (2004). A Web for all reasons: The uses and gratifications of Internet resources for political information. Telematics and Informatics - An interdisciplinary journal on the social impacts of new technologies, 21(3). http://dx.doi.org/10.1016/S0736-5853(03)00037-6 
KIM, J.U. (2008). The Effect of a R/T Group Counseling Program on the Internet Addiction Level and Self-Esteem of Internet Addiction University Students. International Journal of Reality Therapy, 27(2): 4-12.

KO, C.H.; YEN, J.Y.; CHEN, C.C.; CHEN, S.H.; WU, K.; YEN, C.F. (2006). Tridimensional personality of adolescents with Internet addiction and substance use experience. Canadian Journal of Psychiatry, 51: 887-894.

KUBEY, R. W.; LAVIN, M. J.; BARROWS, J. R. (2001). Internet use and collegiate academic performance decrements: Early findings. Journal of Communication, 51: 366-382. http://dx.doi.org/10.1111/j.1460-2466.2001.tb02885.x

LANDERS, R.N.; LOUNSBURY, J.W. (2004). An investigation of Big Five and narrow personality traits in relation to Internet usage. Computers in Human Behavior, 22(2):283-293. http://dx.doi.org/10.1016/j.chb.2004.06.001

LESLIE, E.; SPARLING, P.B.; OWEN, N. (2001). University Campus Settings and the Promotion of Physical Activity in Young Adults: Lessons from Research in Australia and the USA. Health and Education, 101(3): 116-125. http://dx.doi.org/10.1108/09654280110387880

LI, S.M.; CHUNG, R.M. (2006). Internet function and Internet addictive behavior. Computer in Human Behavior, 22: 1067-1071. http://dx.doi.org/10.1016/j.chb.2004.03.030

LOKE, K. (2005). Interpersonal Problems and Interpersonal Expectations in Everyday Life. Journal of Social and Clinical Psychology, 24(7): 915-931.

http://dx.doi.org/10.1521/jscp.2005.24.7.915

MARTIN, M.J. (2001). Impact of Internet abuse for college students. In C. Wolfe (Ed.), Learning and teaching on the World Wide Web (pp. 191-219). San Diego, CA: Academic Press.

MORAHAN-MARTIN, J. (2005). Internet Abuse: Addiction? Disorder? Symptom? Alternative Explanations?. Social Science Computer Review, 23(1): 39-48.

http://dx.doi.org/10.1177/0894439304271533

PAPACHARISSI, Z.; RUBIN, M.A. (2000). Predictors of Internet use. Journal of Broadcasting \& Electronic Media, 44 (2): 175-196. http://dx.doi.org/10.1207/s15506878jobem4402_2

PASTORE, M. (2000). Demographics of the net getting older. Retrieved May 12, 2010, from http://cyberatlas.internet.com/big picture/demographics/article/0,5901 448131,00.html

PEWRESEARCH CENTER (2010). Generations Online in 2010. Retrieved in May, 212012 from http://www.pewinternet.org/2010/12/16/generations-2010/

RANSOM, I. (2007). Chinese boot camps tackle Internet addiction. The New York Times, Monday, March 12. Retrieved from: http://www.nytimes.com/2007/03/12/technology/12ihtaddicts.4880894.html. 
RITTERSKAMP, E. (2003). Let's talk about work ethic. Retrieved January 18th, 2010, from: http://www.atpm.com/8.05/candy.html.

ROTSZTEIN, B. (2003). Problem Internet use and locus of control among college students: Preliminary findings. The 35th Annual Conference of the New England Educational Research Organization. Portsmouth, New Hampshire, April 10.

ROTTER, J.B. (1966). Generalized expectancies for internal versus external control of reinforcement. Psychological Monographs, 80: 1-28. http://dx.doi.org/10.1037/h0092976

ROY, S.K. (2009). Internet uses and gratifications: A survey in the Indian context. Journal of Computers in Human Behavior, 25(4): 878-886. http://dx.doi.org/10.1016/j.chb.2009.03.002

SEBAG-MONTEFIORE, P. (2005). China's young escape into the web. Retrieved April 27th, 2012, from: http://observer.guardian.co.uk/international/story/0,6903,1646663,00.html. The Observer, Sunday 20, November.

SHAPIRA, N.A.; GOLDSMITH, T.D.; KECK, P.E.; KHOSLA, U.M.; MCELROY, M.L. (2000). Psychiatric features of individuals with problematic Internet use. Journal of Affective Disorders, 57: 267-272. http://dx.doi.org/10.1016/S0165-0327(99)00107-X

SCHERER, K. (1997). College life on-line: healthy and unhealthy Internet use. Journal of College and Student Development, 38(6): 655-663.

SHUHAIL, K.; BERGEES, Z. (2006). Effects of Excessive Internet Use on Undergraduate Students in Pakistan. Cyber Psychology \& Behaviour, 9(3): 297-307.

http://dx.doi.org/10.1089/cpb.2006.9.297

SOLOMON, R. (2009). Is Internet addiction real? Retrieved February 16th, 2012, from: http://gadgets. emedia.com.my/product.php?id=340.

SUKUNESAN, S. (1999). Internet Addiction: An Exploratory study amongst Malaysian Internet User. Universiti Putra, Published Master thesis, Malaysia.

THATCHER, A.; GOOLAM, S. (2005). Defining the South African Internet 'addict: Prevalence and biographical profiling of problematic Internet users in South Africa. South African Journal of Psychology, 35: 766-792. http://dx.doi.org/10.1177/008124630503500409

TSAI, C-C.; LIN, S.S.J. (2001). Analysis of attitudes toward computer networks and Internet addiction of Taiwanese adolescents. CyberPsychology \& Behavior, 4: 373-376. http://dx.doi.org/10.1089/109493101300210277

TSAI, C-C.; LIN, S.S.J. (2003). Internet addiction of adolescents in Taiwan: An interview study. CyberPsychology \& Behavior, 6: 649-652. http://dx.doi.org/10.1089/109493103322725432 
UNSAL, F.; RUZGAR, N.S.; RUZGAR, B. (2008). An Empirical Study of Internet Usage, Online Shopping, and Online Banking Behaviour of Turkish University Students. International Trade and Finance Association Working Papers: 22. The Berkeley Electronic Press.

WATTS, J. (2007). China bans opening of new Internet cafes. The Guardian 6 March. Retrieved June 12th, 2010, from: http://www.guardian.co.uk/media/2007/mar/06/chinathemedia.china.

WELLMAN, B.; GULIA, M. (1999). Net surfers don't ride alone: Virtual communities as communities. In B. Wellman (Ed.), Networks in the global village (pp. 331-366). Boulder, CO: Westview.

WIDYANTO, L.; GRIFFITHS, M. (2006). Internet Addiction': A Critical Review. International Journal of Mental Health and Addiction, 4: 31-51. http://dx.doi.org/10.1007/s11469-006-9009-9

WILLIAMS, R. (2008). China recognises Internet addiction as new disease. The Guardian. Retrieved June 24th, 2011, from: http://www.guardian.co.uk/news/blog/2008/nov/11/chinaInternet? INTCMP=ILCNETTXT3487.

YANG, S.C.; TUNG, C.J. (2004). Comparison of Internet addicts and non-addicts in Taiwanese high school. Computers in Human Behaviour, 23: 79-76.

http://dx.doi.org/10.1016/j.chb.2004.03.037

YOU, H.S. (2007). The effect of Internet addiction on elementary school student's self-esteem and depression. Unpublished master's thesis, Chungnam: The Graduate School of education of Kongju University.

YOUNG, B. (2006). A study on the effect of Internet use and social capital on the academic performance. Journal of Development and Society, 35(1): 107-123.

YOUNG, K. (2010). Policies and procedures to manage employee Internet abuse. Computers in Human Behavior, 26(6): 1467-1471. http://dx.doi.org/10.1016/j.chb.2010.04.025

YOUNG, K. S. (1999). Internet Addiction: Symptoms, Evaluation, and Treatment. Innovations in Clinical Practice, 17: 1-17.

YOUNG, K.S. (1998). Internet addiction: The emergence of a new clinical disorder. CyberPsychology \& Behavior, 1: 237-244. http://dx.doi.org/10.1089/cpb.1998.1.237

YOUNG, K.S. (2001). Tangled in the web: Understanding Cybersex from Fantasy to Addiction. Bloomington, Indiana: Authorhouse.

YOUNG, K.S. (2004). Internet Addiction: A New Clinical Phenomenon and Its Consequences. American Behavioral Scientist, 48: 402-415. http://dx.doi.org/10.1177/0002764204270278

YOUNG, K.S. (2008). Internet Sex Addiction: Risk Factors, Stages of Development, and Treatment. American Behavioral Scientist, 52: 221-237. 
ZDNET RESEARCH (2006). Internet activities by age group. Retrieved June, 15th, 2012, from http://www.zdnet.com/blog/itfacts/internet-activities-by-age-group/10025

Intangible Capital, 2014 (www.intangiblecapital.org)

Article's contents are provided on a Attribution-Non Commercial 3.0 Creative commons license. Readers are allowed to copy, distribute and communicate article's contents, provided the author's and Intangible Capital's names are included. It must not be used for commercial purposes. To see the complete license contents, please visit http://creativecommons.org/licenses/by-nc/3.0/. 